\section{Coesão social e integração regional: a agenda social do MERCOSUL e os grandes desafios das políticas sociais integradas}

\author{
Social cohesion and regional integration: the \\ MERCOSUR social agenda and the integrationist \\ social policy major challenges
}

Sônia Miriam Draibe 1

\section{Introdução} ${ }^{1}$ Núcleo de Estudos Universidade Estadual de Campinas, Campinas, Brasil.

Correspondência S. M. Draibe Núcleo de Estudos de Políticas Públicas

Universidade Estadual de Campinas.

Rua São Vicente de Paula 526, apto. 91, São Paulo, SP 01229-010, Brasil.

smdraibe@uol.com.br

\begin{abstract}
In the consolidation of the Southern Cone Com-
Abstract mon Market (MERCOSUR), social policies are still in the embryonic stage. However, since the latter half of the 1990s there has been a speedup in the creation of institutions dedicated to such policies with the Common Market's framework. This article focuses on health policy and the broader social policy system in order to identify the reasons for the imbalance, through three movements: reconstitution of the history of the institutional construction of social policies in MERCOSUR; identification and comparison of the successive strategies for the formulation and implementation of the social integration agenda; and reflection on the current dilemmas and challenges faced by the process. According to the study, MERCOSUR operates with strategies that are difficult to mutually reconcile. On the institutional level, it follows a minimalist strategy, while on the conceptual/ discursive level it adopts a maximalist strategy for supranational unification of social policies. The fact is that it operates a minimalist social policy strategy, since it fails to bring to the field of social integration the debate and proposals on economic and social development models that could sustain the effective construction of regional social citizenship.
\end{abstract}

Health Policy; Public Policy; Economic Development
É trivial e recorrente a observação de que as políticas sociais se encontram em estágio embrionário nos processos constitutivos do MERCOSUL e isto é verdade, embora desde a metade dos anos 1990 tenham sido criadas, multiplicadas e fortalecidas no interior do sistema as instituições a elas dedicadas. Ora, é sabido que pelo menos as políticas de saúde e de educação integram o núcleo estratégico dos vários processos de integração regional, desde os primeiros momentos de mera unificação aduaneira, dadas as suas especiais relações com as questões de circulação de mão-de-obra e de produtos.

Como entender então, no caso do MERCOSUL, o referido atraso e, ao mesmo tempo, o reconhecido avanço institucional registrado na agenda social da integração nos últimos anos? Atraso ou avanço estaria sendo medido em relação a quais metas ou objetivos? No plano do senso comum, plano aliás no qual mais freqüentemente são feitas essas referências, trata-se de uma comparação com outras áreas e campos de políticas, as quais registram progresso bem mais acentuado, como são os casos das políticas comerciais, aduaneiras, industriais, agrícolas etc. Nesse plano, o atraso na construção das instituições da política social de integração é verdadeiro, ainda quando os avanços recentes são levados em conta.

Outro sentido, mais forte e substantivo, diz respeito ao processo mesmo de construção insti- 
tucional de políticas sociais unificadas no âmbito do Mercado Comum. Atraso e progresso, aqui, estariam referidos ao quanto já se teria caminhado na institucionalidade de um sistema comum de proteção social, de programas e políticas sociais integradas.

Unificação das políticas sociais e, de modo mais ambicioso, a criação de uma cidadania social comunitária, apoiada em direitos e sistemas comuns de proteção social, têm sido crescentemente propostos como horizonte e metas do MERCOSUL social por parte dos atores-chave que militam no processo de sua fundação, sejam representantes de governos dos países membros, sejam as organizações da sociedade civil. Ninguém duvida de que, ante tais objetivos, nos encontramos ainda a enormes distâncias.

Mas até que ponto a suposição de tal horizonte e daquelas metas constitui o melhor ou o mais adequado tratamento da questão social no âmbito da integração regional? Integrar e unificar políticas e programas sociais de nenhum modo é processo simples, menos ainda fácil, que dependesse tão somente das vontades políticas dos governantes. Em relação a eles, é de se esperar que tanto agora quanto certamente no futuro longínquo, atrasos e déficits se verificarão sistematicamente, como bem mostra a experiência tão mais antiga da União Européia.

Além de questionar a possibilidade e a factibilidade de tais objetivos, cabe perguntar se tal modo de tratamento da questão social constitui uma boa estratégia político-institucional para alcançar os objetivos maiores de compensar os efeitos sociais negativos da integração e, sobretudo, de maximizar seus benefícios no tocante às condições sociais de vida e de trabalho dos cidadãos dos países membros.

Afinal, as posições débeis e a baixa eficácia das políticas sociais também caracterizam internamente os países membros. Menos por déficit de institucionalidade dos sistemas nacionais de políticas sociais, sempre presentes, como se sabe, ou porque a política social ocupa, via de regra, um lugar marginal ou dependente da política econômica, antes por carecer ela de uma maior integração com a própria política econômica. Mais que independência e autonomia, seu fortalecimento parece depender do aprofundamento dos seus vínculos com a política econômica, em um modelo de crescimento econômico no qual e a partir do seu próprio centro, a política social opere como sistema de proteção social e simultaneamente como fator produtivo, isto é, como alavanca do próprio crescimento. Ora, essa é uma estratégia pertinente não somente à política econômica, mas também e quem sabe principalmente, à política social.
É com preocupações dessa natureza que, neste trabalho, examinamos a dimensão social do MERCOSUL. Na Seção O MERCOSUL Social: $O$ Estado Atual da Questão, procedemos a um breve registro do estado-das-artes ou da situação atual da agenda social da integração, para em seguida, na Seção O MERCOSUL Social: Observações sobre as Incoerentes Estratégias Maximalistas e Minimalistas da Integração, refletir sobre as estratégias e os limites da integração social almejada, segundo alguns temas selecionados.

\section{O MERCOSUL social: o estado atual da questão}

Ao longo dos anos 90, a questão social da integração ampliou-se e ganhou centralidade na agenda do MERCOSUL sob distintas perspectivas, por meio de um processo de indubitável aprofundamento do tema, ao qual não faltaram expressões intelectuais e institucionais.

Tal movimento se desenvolveu através de dois eixos principais. De um lado, ocorreu um processo de densificação institucional na esfera social do MERCOSUL por meio da criação de novas e diversificadas instituições especificamente dedicadas à dimensão social. De outro, o amadurecimento e a ampliação conceitual caracterizaram o percurso intelectual e estratégico com que os temas sociais da integração vêm desde então sendo tratados. Vejamos com algum detalhe o desenvolvimento desses dois eixos.

\section{O desenvolvimento institucional} da dimensão social do mercado comum

A questão social não contou com qualquer institucionalidade própria na primeira etapa de constituição do MERCOSUL. Com efeito, apenas em 1991, por pressão das entidades sindicais e outras organizações da sociedade civil, agregouse aos dez primeiros 10 subgrupos de trabalho instituídos pelo Tratado de Assunção, o subgrupo Relações Laborais, Emprego e Previdência Social, referido como Subcomissão 11, protagonista praticamente exclusiva da dimensão social da integração até 1995, quando se transformou no Subgrupo 10 - Relações Laborais, Emprego e Seguridade Social, abrindo espaço para a criação, em 1996, do Subgrupo de Trabalho 11 Saúde (SGT 11). O tema do meio ambiente foi objeto de Reuniões Especializadas (REMA), entre 1993 e 1995, posteriormente transformadas, por demandas de técnicos governamentais e de ONGs, no SGT 62 .

Já no período subseqüente, foram firmados importantes marcos legais e criadas novas insti- 
tuições, especificamente voltados para os temas da integração social. As principais medidas, segundo cronología correspondente, estão citadas na Tabela $12,3,4$.

$\mathrm{O}$ avanço é notório, traduzido na diversificação de objetivos e funções da nova institucionalidade em que se apoia hoje a dimensão social do MERCOSUL, como bem mostra o competente resumo da história institucional do MERCOSUL Social elaborado por Di Pietro Paolo 2. Mais ainda, vale lembrar que tal progresso e amadurecimento institucional foi estimulado e acompanhado pela mobilização e paulatina integração de organizações da sociedade civil nos seus foros privilegiados, ampliando-se assim a participação social no espaço do mercado comum. O caso setorial da política de saúde exemplifica bem tal processo, como se vê brevemente a seguir.

\section{A política de saúde no MERCOSUL}

Também em relação à política de saúde, os avanços institucionais foram importantes 5,6,7. Criado em 1996, o SGT 11 Saúde tem por objetivo: "harmonizar as legislações dos Estados Partes referentes aos bens, serviços, matérias-primas e produtos da área da saúde, os critérios para a vigilância epidemiológica e controle sanitário com a finalidade de promover e proteger a saúde e a vida das pessoas e eliminar os obstáculos ao comércio regional, contribuindo dessa maneira ao processo de integração" 8 .

Para o cumprimento de tais tarefas, o SGT 11 Saúde foi estruturado nas seguintes comissões e subcomissões: Comissão de Produtos para a Saúde; Comissão de Vigilância Epidemiológica e Controle Sanitário (de portos, aeroportos, terminais e pontos de fronteira); Comissão de Serviços de Atenção à Saúde; Subcomissão de Serviços de Saúde; Subcomissão de Desenvolvimento e Exercício Profissional; e Subcomissão de Avaliação e Uso de Tecnologia em Saúde.

Por sua vez, a Reunião de Ministros de Saúde do MERCOSUL e Estados Associados - fórum para discussão das macropolíticas e estratégias para o setor saúde - define pautas negociadoras baseadas em estrutura de projetos e planos comuns consubstanciada em diversas comissões intergovernamentais conjuntas nos temas de: Políticas de Medicamentos; Programa de Vigilância e Controle de Doenças Transmissíveis, Sarampo, Cólera, Dengue e Febre Amarela; Controle da Dengue; HIV/AIDS; Saúde Sexual e Reprodutiva; Controle do Tabaco; Saúde e Desenvolvimento;

Tabela 1

Principais marcos legais e instituições relacionadas à integração social no MERCOSUL.

\begin{tabular}{|c|c|}
\hline Ano & Marcos legais e instituições \\
\hline 1995 & Fórum Consultivo Econômico e Social (FCES) \\
\hline 1995 & Rede MERCOCIDADES \\
\hline 1996 & Sistema de Informação em Educação no MERCOSUL \\
\hline 1996 & Criação do SGT 11 Saúde (Resolução GMC no. 151/1996) \\
\hline 1997 & Tratado Multilateral de Seguridade Social \\
\hline 1997 & Observatório do Mercado de Trabalho \\
\hline 1998 & Declaração Sócio-Laboral do MERCOSUL (SGT 10) \\
\hline 1999 & Comissão Sócio-Laboral (órgão auxiliar do Grupo MERCOSUL - GMC) \\
\hline 2000 & Carta Social do MERCOSUL \\
\hline 2000 & Institucionalização da reunião de ministros e autoridades de desenvolvimento social \\
\hline 2000 & Institucionalização da reunião especializada de municípios e intendências \\
\hline 2000 & Proposição da elaboração da agenda social da integração (Declaração de Rosário) \\
\hline 2001 & Sistema Estatístico de Indicadores Sociais (SEIS) \\
\hline 2002 & Grupo ad hoc de Integração Fronteiriça \\
\hline 2003 & Proposição da elaboração do Programa de Fortalecimento do MERCOSUL Social \\
\hline 2003 & Recomendações práticas sobre formação profissional \\
\hline 2004 & Primeira Conferência Regional de Emprego \\
\hline 2004 & Recomendação sobre uma Estratégia MERCOSUL para a criação de emprego \\
\hline 2004 & Grupo de alto nível para a elaboração de uma estratégia MERCOSUL sobre crescimento do emprego \\
\hline 2005 & Fundo Social Especial \\
\hline
\end{tabular}

Fonte: Elaborada com base em Di Pietro Paolo 2, Podestá 3 e Draibe 4. 
Gestão de Riscos e Redução de Vulnerabilidades; Saúde Ambiental e do Trabalhador; Implementação do Regulamento Sanitário Internacional; Doação e Transplantes; Sistema de Informação e Comunicação em Saúde; e Banco de Preços de Medicamentos do MERCOSUL.

No caso da saúde, como se vê, foram também importantes os avanços institucionais. Os analistas chamam mesmo a atenção para progressos na pauta negociadora, relativos ao campo dos sistemas de informações e comunicação; da vigilância e controle de infestação por Aedes aegypti e da transmissão do vírus do dengue; na luta contra a epidemia de HIV/AIDS; na gestão de riscos e redução de vulnerabilidades e em temas de saúde e desenvolvimento. E ainda no tocante às políticas integradas de saúde sexual e reprodutiva; controle do tabaco; saúde ambiental e saúde do trabalhador; medicamentos (inclusive o banco de preços); vigilância e controle de doenças transmissíveis (sarampo, cólera, dengue e febre amarela) e implementação do regulamento sanitário internacional 5,9.

Mas as dificuldades são muitas e o processo de integração tem sido gradual e lento, circunscrito principalmente às questões relacionadas à circulação de produtos e às ações de saúde pública de alta externalidade, tais como as de vigilância sanitária e epidemiológica 10 . De certa maneira, permanecem abertos e em vigências, no campo da saúde no MERCOSUL, os mesmo problemas já apontados desde 1999 em documento do Ministério da Saúde: “(a) falta o livre comércio de serviços - 'Prestação de Serviços de Saúde’ e de Produtos para Saúde; (b) a área de livre circulação de pessoas é incipiente, aqui entra toda a questão do 'Exercício Profissional'; (c) a questão da Vigilância Epidemiológica e Sanitária para prevenir e evitar a disseminação de doenças; (d) já houve avanço no livre comércio de bens, mas falta muito para a livre circulação de bens (aqui entra as assimetrias dos sistemas de regulamentação técnica e as medidas sanitárias e fitossanitárias entre os países), apesar do muito que já foi feito numa quantidade grande de setores, entre os quais Alimentos e Medicamentos" 11 (p. 22).

Ou seja, de algum modo, também a política de saúde revela a contradição inicialmente apontada entre o relativo avanço do processo da construção institucional e o atraso significativo em matérias substantivas da integração.

É possível examinar as raízes de tal descompasso nas idiossincrasias tanto dos Países Membros quanto das próprias áreas de políticas envolvidas. Preferimos, neste trabalho, examinar a questão pelo ângulo mais geral dos conceitos e entendimentos que têm norteado, nos últimos anos, o equacionamento da questão social da integração, por entender que aí residem alguns dos fatores que têm contribuído para o contraditório processo de formação e implementação da agenda social da integração.

\section{Conceitos e entendimentos da dimensão social da integração: desenvolvimentos recentes}

Do ponto de vista substantivo, é inegável o caráter mais abrangente com que se define ou se conceitua, atualmente, a dimensão social.

Como já registramos em outro trabalho 4 , o MERCOSUL não nasceu com uma agenda social dotada de autonomia, embora certas dimensões sociais da integração tenham estado obviamente presentes em suas preocupações originais. Com efeito, os temas sociais praticamente estiveram reduzidos, até há poucos anos, aos direitos laborais e, mais recentemente ainda, a alguns aspectos previdenciários e de saúde, debatidos e entendidos quase sempre, entretanto, enquanto componentes da agenda multilateral de comércio, considerados na verdade como elos dos acordos comerciais e dos processos facilitadores da circulação dos trabalhadores. E mesmo no seu desenvolvimento posterior, foi sob o signo da "cláusula social" que problemas como os da proibição do trabalho infantil, do trabalho escravo ou o da liberdade sindical foram prioritariamente tratados.

Impulso importante ao alargamento intelectual e valorativo da agenda social real do MERCOSUL foi dado, da metade dos noventa em diante, pela incorporação de alguns dos temas centrais da agenda internacional: o compromisso, ou a referência da integração aos valores do Estado de Direito e, mais amplamente, da democracia, e também a perspectiva dos direitos humanos, no quadro mais amplo de um modelo de desenvolvimento econômico regional, pautado pela justiça e pela eqüidade. Em outros termos, verificou-se um processo intelectual de atualização, ampliação e complexização do marco geral no qual se definem hoje os objetivos da integração social.

A agenda social, especificamente, registra alargamento da mesma natureza. Em primeiro lugar, porque o tema do emprego pareceria extrapolar os limites da sua mera proteção contra os efeitos negativos da integração, avançando para um tratamento mais amplo e sintonizado com as realidades atuais dos mercados nacionais de trabalho, tão fortemente afetados pelo desemprego, a baixa qualificação e as pressões da competitividade e da integração. Em segundo lugar, chama a atenção a força com que os temas da pobreza e da 
inclusão social comparecem no discurso oficial do Mercado Comum, em matéria social.

Um exemplo disso pode-se tomar da Declaração do Conselho do Mercado Comum (reunião de junho de 2003), quando registra “... a necessidade de priorizar a dimensão social do MERCOSUL para incentivar o desenvolvimento com eqüidade dos Estados Partes e da região em seu conjunto, com ênfase naquelas medidas tendentes a propiciar a inclusão social e econômica dos grupos mais vulneráveis da população. Na área laboral (...) a necessidade de adotar medidas para erradicar o trabalho infantil, facilitar a livre circulação de trabalhadores e incluir o tema do emprego como objetivo na agenda da integração" 12 .

Passo importante se dá enfim com a explicitação, no discurso de representantes de alguns dos países membros, da meta de construção de uma cidadania social, do mesmo modo que a aspiração de se adotar uma estratégia institucional da integração social por meio de políticas sociais unificadas.

A referência a uma cidadania supranacional, comunitária, não é nova, e tem operado sobretudo como marco referencial da meta da livre circulação das pessoas e de seus direitos. Tampouco é novidade, no discurso do MERCOSUL, o conceito de cidadania laboral, referido ao espaço social da integração e aos mecanismos limitadores do risco do dumping social. Entretanto, não se efetivou, até agora, a correspondente construção institucional, nem mesmo nos planos jurídico e legal da definição de uma normativa laboral internacional mínima comum ${ }^{13}$.

De maior abrangência pareceria ser o conceito de cidadania social e o objetivo de se processar a integração social no plano de políticas sociais unificadas. O conceito de cidadania social é tributário, em alguma medida, das bandeiras mobilizadoras dos movimentos sociais e das ONGs atuantes no plano global e orientadas por posições críticas aos processos da globalização. Enquanto eixos de mobilização, sem dúvida guardam pertinência com o processo integrador do MERCOSUL, em especial no que diz respeito à defesa de direitos, à redução dos impactos negativos da integração e à ampliação da participação social por meio da incorporação das organizações da sociedade civil naquele processo.

Mas seu significado pareceria extravasar esse nível de entendimento, especialmente quando se vincula o conceito de cidadania social à estratégia de unificação dos sistemas de políticas sociais, como se verifica em alguns discursos e proposições. A cidadania social, neste sentido mais forte, pareceria estar referida a direitos sociais mínimos e comuns, apoiados e garantidos por políticas sociais integradas ou unificadas.
Ora, o que significam políticas sociais unificadas, no espaço da integração regional? É verdade que propostas como essas restringem-se ao plano do discurso, com poucas ou quase nulas referências a seus substratos e conteúdos. De todo modo, é possível supor ou identificar dois sentidos nesta proposição. O primeiro, menos forte, estaria referido às medidas de harmonização, entre os países, de suas políticas sociais, caminho já parcialmente seguido ou em curso, por exemplo por meio de tratados bilaterais de complementação mútua de políticas sociais, como o celebrado entre Brasil e Argentina dois ou três anos atrás. O exemplo mais claro é o da educação, respeito às medidas visando à compatibilização dos créditos, diplomas e níveis de escolaridade.

O segundo sentido é mais forte, uma vez que supõe ou leva a supor a unificação stricto senso das políticas sociais, ou seja, uma efetiva convergência das mesmas, um processo de igualação de seus programas, em conteúdo, forma e mesmo instituições. Em certo sentido, uma verdadeira cidadania social supranacional, fundada em direitos sociais mínimos comuns, exigiria, para se efetivar, um tal processo unificador ou igualador de políticas sociais.

A proposição se revela tão mais ambiciosa quando confrontada com o modesto avanço do MERCOSUL social. Como já nos referimos, além de acordos sobre seguridade social e direitos do trabalho, pouco se tem caminhado, até mesmo no tocante às definições e conteúdos da agenda social da integração.

Com efeito, reconhecendo tais insatisfatórios resultados, desde meados de 2002 tanto o grupo técnico da reunião de ministros e autoridades responsáveis pelo desenvolvimento social do MERCOSUL, Bolívia e Chile quanto os chanceleres do MERCOSUL (reunidos em Montevidéu em fevereiro de 2003) passaram a conferir alta prioridade ao desenvolvimento social, ao combate à fome e à pobreza. E reafirmaram a necessidade de se dar corpo ao Programa de Fortalecimento do MERCOSUL Social, por meio de políticas econômicas e sociais inclusivas, voltadas para a redução da pobreza e da desigualdade na região.

Para sua viabilização institucional, concebida como condição prévia da ainda indefinida Agenda Social, propôs-se a elaboração de uma Agenda Institucional do MERCOSUL, visando aos seguintes objetivos: (i) explicitar a visão e os objetivos gerais e específicos do MERCOSUL Social, no contexto do processo de integração regional; (ii) estabelecer o marco no qual se desenvolverá o Programa de Fortalecimento do MERCOSUL Social. Afirmava-se ao mesmo tempo a necessidade de criação de um Fundo MERCOSUL Social, 
formado por contribuições dos países membros e associados.

Mais recentemente, outro reconhecimento e tentativa de correção das debilidades do processo foi o estabelecimento das comunidades fronteiriças como prioridade a se observar na estratégia incremental de implementação da Agenda Social. Junto a esse primeiro público-alvo, buscar-se-ia facilitar a documentação e a circulação das pessoas e dos trabalhadores, assim como assegurar os direitos à assistência, à saúde e à seguridade social.

Mesmo reconhecendo nos fatos algum avanço, não se pode perder de vista que os resultados são notoriamente modestos em matéria de integração social.

A integração social, na perspectiva das políticas e programas sociais, é sabidamente um difícil processo e, a este respeito, o MERCOSUL não é único, como provam as dificuldades da União Européia.

Por isso mesmo, chama a atenção, no caso do MERCOSUL, menos o "atraso" da integração social, antes o forte contraste entre uma evolução conceitual e institucional bastante favorável, audaciosa e até mesmo relativamente exitosa, como tratamos de enfatizar, e os modestíssimos resultados já alcançados na concretização da integração social.

Quais as principais dificuldades ou obstáculos que estariam impedindo tal processo? Para além dos conhecidos fatores que costumam incidir sobre os processos de integração - os conflitos políticos e de interesses, as idiossincrasias nacionais, a força de inércia que em geral caracteriza os câmbios institucionais - gostaríamos de tecer algumas considerações especificamente sobre as estratégias propostas para o avanço do movimento de integração social, perguntando-nos até que ponto aí também podem ser identificados obstáculos ou limites à aceleração do processo.

\section{O MERCOSUL social: observações sobre as incoerentes estratégias maximalistas e minimalistas da integração}

Uma agenda complexa e sobrecarregada de integração social, como pareceria ser o caso da Agenda Social do MERCOSUL, exige instituições internacionais novas e suficientemente fortes tanto para lograr seus patamares mínimos - o reconhecimento dos direitos, títulos e créditos sociais das pessoas que se movem no espaço -, quanto e mais ambiciosamente para criar e garantir os novos direitos sociais, correspondentes à nova cidadania social que se quer instituir na região.
A leitura do processo examinado na seção anterior permite afirmar que o MERCOSUL trata de conciliar ou harmonizar duas estratégias de escopo ou ambição distintas. No plano das instituições da política social da integração, opera com uma estratégia minimalista, de baixa efetividade, enquanto que no plano dos conceitos e objetivos da integração, opera com uma estratégia maximalista, apontando para um nível supranacional de unificação das políticas da proteção social. Ou seja, propõe o máximo em termos de conteúdo (a cidadania social sob políticas sociais unificadas) e o mínimo de instituições (ou nenhuma, na prática), que viabilizariam tal conteúdo.

Por outro lado, no plano estratégico, o MERCOSUL opera com uma estratégia maximalista da dimensão social, referida aos objetivos da integração, mas ao mesmo tempo, com uma estratégia minimalista de políticas sociais, uma vez que abdica de trazer para o campo da integração social o debate e a proposição de modelos de desenvolvimento econômico e social que pudessem sustentar, mais adequadamente, um efetivo processo de constituição de uma cidadania social nova e coesa. Alguns dilemas e impasses da implementação de uma efetiva Agenda social regional repousam, a nosso ver, nas contradições dessas desencontradas estratégias e definições. É o que comentamos nas seções seguintes.

\section{Ambiciosos objetivos assentados em frágil institucionalidade: dilemas institucionais do MERCOSUL social}

A estratégia minimalista, em termos institucionais, parece ser até agora uma das opções preferenciais do processo de integração do MERCOSUL, tanto mais visível quando comparada a outros processos, especialmente o da construção da União Europa (EU). Em que medida o processo se enfrenta efetivamente com problemas de déficit institucional e até quando prevalecerá a regra dos consensos intergovernamentais - e não a de instituições supranacionais -, estes são temas que, como se sabe, dividem as opiniões dos países, e a lógica de seu encaminhamento é quase que exclusivamente política. Mas a questão guarda especial importância para a dimensão social da integração, merecendo por isso algumas observações.

Do mesmo modo que em outros domínios da integração, o núcleo da construção do MERCOSUL social gira em torno do binômio igualdade versus distinção: as instituições da integração social, constituídas no plano supranacional, pautar-se-iam pela igualdade, ou seja, obedeceriam à regra de não se constituírem nem 
serem percebidas como qualquer ameaça à soberania dos Países Membros.

Essa é, ademais, a regra de ouro da estratégia de construção institucional, apoiada no reconhecimento de que: (i) os Estados cooperantes são pressionados a todo momento por seus grupos internos de interesses, que buscam ocupar posições vantajosas (ou protegidas) vis-à-vis os grupos simétricos dos outros países; (ii) em conseqüência, o processo de integração é necessariamente conflitivo e tenso, que deve insistentemente buscar estratégias convergentes de integração, e não a distinção, sob a forma da hegemonia de uma estratégia nacional sobre as outras 14

Nesse particular, o desafio institucional é enorme. Isso porque, pelo menos em teoria, uma tal estratégia de convergência supõe instituições supranacionais fortes e ao mesmo tempo "construtivas”, isto é, capazes de manejar os conflitos e de garantir aos Estados cooperantes as vantagens da integração, evitando a configuração de "grupos de perdedores" que, no momento seguinte, possam vetar o avanço do processo de integração 14 . No caso da integração social, estamos falando de instituições capazes de enfrentar adequadamente pelo menos as seguintes questões: (i) para quais níveis de proteção devem convergir as regras, e a quais estratégias de desenvolvimento sócio-econômico corresponderiam?; (ii) com que graus de centralismo e de "supranacionalidade" devem e podem ser dotadas as novas instituições, e a quais estratégias de articulação institucional corresponderiam?; (iii) em quais atores estratégicos haveriam de se apoiar, de modo a reforçar sua representatividade e legitimidade internacionais e nacionais?

A primeira questão está diretamente relacionada à ambição do MERCOSUL social, a de criar uma cidadania social, uma proteção social básica a todos os cidadãos da região. Entretanto, em que níveis se estabeleceria uma tal proteção social? No nível dos sistemas de proteção social menos desenvolvidos, ou ao contrário, daqueles mais completos e abragentes, entre os países da região?

Ora, sabe-se que a força da competição entre os estados nacionais parece impulsionar a convergência das regras e benefícios para um nível mínimo (próximo aos níveis dos países mais atrasados, em matéria de políticas sociais), o que configuraria uma sorte de "ajustamento para baixo", quase sempre implicando o dumping social. Por outro lado, a alternativa de "ajustamento para cima”, segundo o nível de proteção social dos países mais desenvolvidos, tende a enfrentar dificuldades enormes, principalmente quando os países se encontram, como agora, sob fortes pressões fiscais. Dificuldades presentes mesmo quando a integração obedece a um programa lento e incremental de convergência das normas, prestações e benefícios.

Tal como se pode verificar na experiência da UE, na verdade essas duas formas de ajustamento correspondem a duas estratégias diferentes de redução das diferenças entre os países cooperantes. De um lado, a estratégia da "convergência por baixo" consistiria em possibilitar que as diferenças dos custos de mão-de-obra joguem a favor dos países menos desenvolvidos (do sul da Europa, por exemplo), de forma que enriquecendo a uma velocidade mais rápida que os outros, reduzam o gap de seus sistemas de proteção social em relação ao dos países mais desenvolvidos (do norte da Europa), a convergência se estabelecendo aqui em níveis médios. De outro lado, a estratégia de "convergência pelo alto" busca a redução das diferenças através de mecanismos redistributivos, do tipo dos fundos estruturantes de desenvolvimento, promotores de uma maior homogeneidade social 15 . Seria possível pensar na planejada e harmônica convivência dessas duas estratégias, no caso dos países do Mercado Comum? Que tipo de instituições poderiam viabilizá-las? O recém-aprovado Fundo Social Especial (2005), voltado ao combate à pobreza, poderá cumprir as funções homogeneizadoras de um fundo estruturante?

O segundo problema, relativo à natureza político-institucional das instituições internacionais da política social, tem como preocupação central a compatibilização da integração e das diversidades nacionais em termos dos sistemas de proteção social, capazes de presidir estratégias convergentes de longo prazo. O debate mais sugestivo, a esse respeito, insiste nas boas potencialidades do arranjo federativo para viabilizar compatibilização requerida, caminho aliás seguido pela UE por meio de um Estado que intervém essencialmente por meio de normas globais (diretivas) às quais se ajustam os Estados membros, preservando suas iniciativas em relação ao "como fazer”, mas submetendo-se à ação supervisora e reguladora das agências comunitárias 15,16. Haveria para o MERCOSUL um futuro institucional dessa natureza? As instituições supranacionais até agora criadas - o Fórum Econômico e Social e outras - ao que parece carecem de formato ou capacidade para operações dessa natureza.

Finalmente, o terceiro problema refere-se aos atores estratégicos que atuam tanto nos processos de construção institucional como nos espaços de representação que, uma vez criados, se abrem à sua atuação. O que distingue instituições fracas de instituições fortes é o capital social ali acumulado: as redes de compromisso, os valores, 
as bases de confiança e de legitimidade, as boas e competentes regras de ação. Dimensões que são sobretudo resultado da mobilização social que sustentou e que poderá sustentar no futuro a mudança institucional e, mais amplamente, a construção de novas institucionalidades. Quem são, entretanto, os atores estratégicos que podem ser mobilizados no processo de construção das instituições inovadoras da integração social?

Podestá 3 já havia chamado a atenção para a diversidade de atores sociales envolvidos na temática da integração social no âmbito do MERCOSUL: empresários e trabalhadores sindicalizados, desde logo, mas também segmentos de trabalhadores conectados com o setor informal; os colégios profissionais; as organizações de mulheres; as associações de defesa do meio ambiente; as ONGs envolvidas com as distintas dimensões e áreas das políticas sociais etc. Ora, são conhecidas as dificuldades de representação dessa gama variada e fragmentada de interesses, tanto no plano interno dos países como em espaços como o Fórum. Afinal, quem são os representantes e a quem representam? Através de quais mecanismos são identificados e selecionados? Com que amplitude de temática (temas, objetivos, dimensões) vão se enfrentar?

Colocando o tema com cores mais fortes, poder-se-ia afirmar que, ou bem o processo de construção institucional conta com a mobilização social desses atores, ou as instituições criadas burocraticamente seguirão proliferando sob o signo da fragilidade, senão da ilegitimidade. Condições decididamente negativas para o processo de integração com a eqüidade que se pretende fazer avançar no espaço social do MERCOSUL.

O centro da agenda: políticas sociais unificadas $\mathrm{X}$ modelo de desenvolvimento econômico-social

É possível unificar sistemas de políticas sociais em processos de integração regional? O que ensina a experiência internacional a respeito?

Tal como já nos referimos anteriormente, o reconhecido atraso do processo de integração social do MERCOSUL está, implícita ou explicitamente, referido à distância que o separa dos objetivos declarados da integração - a constituição de uma cidadania social e a unificação das políticas sociais.

É verdade que o processo de construção institucional do MERCOSUL social caminhou com relativa agilidade nos últimos cinco ou sete anos, mas é verdade que não somente os resultados concretos da integração se mostram modestos e limitados, também suas instituições não parecem adequadamente desenhadas e capacitadas para tratar dos problemas centrais e não burocráticos da integração.

Mas pode-se pensar que os insatisfatórios resultados poderiam ser superados por meio de melhores e mais capazes instituições? Sim e não. Obviamente é necessário e possível avançar na engenharia institucional que facilitará a circulação das pessoas na esfera regional. Mas dificilmente se logrará, por esse meio, uma efetiva unificação de políticas sociais, no sentido forte sugerido na nova gramática da integração. Nesse caso, mais que um atraso do MERCOSUL, quiçá se trate aqui de uma inadequada ou até mesmo equivocada estratégia. A lição internacional, a respeito, é ainda instigante.

Com efeito, o processo de construção da UE mostra, com abundantes evidências, que convergência ou unificação constituem processos bastante factíveis e viáveis em arenas tais como as das políticas econômicas e financeiras, a política aduaneira, a política comercial, o campo das regulamentações jurídicas etc., mas se revelaram e ainda se revelam praticamente impossíveis no campo das políticas sociais - como registrou, aliás, o fracassado intento de Maastrich. Na área social, onde mais se avançou - na política de seguridade social - o progresso somente se mostrou possível quando foi também abandonada a estratégia de convergência forte, de modelo unificado de proteção, a ênfase se deslocando para o campo do reconhecimento dos direitos, das equivalências e das transferências.

E em políticas como educação e saúde, os limites parecem quase infranqueáveis, quase tabus, que na prática obrigam os comunitários europeus a retirar de seus discursos ou proposições qualquer referência a convergências, mais ainda a projetos de unificação. A harmonização de políticas pareceria, então, se constituir no objetivo-limite nas áreas de políticas dotadas de forte institucionalidade, de amplas burocracias, de enraizadas tradições e culturas institucionais, enfim, de história e de características nacionais. É verdade que a integração social européia progrediu, mas os avanços e atrasos registrados não podem ser medidos pelo metro de objetivos unificadores impossíveis, e sim pelo patamar de coerência, harmonização e intercomunicabilidade das políticas.

Há razões mais profundas que apontam ou sugerem erros estratégicos, no caso do MERCOSUL, quando localiza no centro de sua agenda social (real) o objetivo (inalcançável) da unificação de políticas como condição da criação da nova cidadania social. Alcançar graus significativos e sustentados de coesão e bem-estar social na região - base da almejada cidadania social - não se logra automaticamente pela mera 
integração burocrática de sistemas de políticas sociais, mesmo que isto fosse viável. Importa e muito a qualidade, o modelo de políticas sociais, desde logo, e já nos referimos às variações de abrangência e generosidade de sistemas de proteção social mais ou menos desenvolvidos, entre os países da região. Mas para alcançar aqueles objetivos de bem-estar social integrado, parece importar e mais ainda, o próprio modelo de desenvolvimento econômico e social dos países membros, um modelo que, diferentemente do cenário atual, inclua e privilegie o progresso social nas suas próprias metas econômicas.

Além de razões de eqüidade, de igualdade, de coesão e inclusão social, há razões econômicas que justificam uma tal proposição, apontando para argumentos que sublinham a importância, nos tempos atuais, de se criarem alternativas ou modelos de desenvolvimento econômico que sejam ao mesmo tempo economicamente dinâmicos, politicamente democráticos e socialmente inclusivos 17. Em outros termos, mais que a política social em si, e sua unificação, são suas vinculações com a política econômica as que mais decisivamente deveriam constituir o centro nevrálgico da Agenda Social do MERCOSUL.

Do ponto de vista das políticas sociais, trata-se de buscar um sistema de proteção social no sentido amplo que, nas suas interações com o tecido econômico, opere como uma alavanca tanto para o crescimento da economia quanto e ao mesmo tempo para a promoção da maior igualdade entre os cidadãos. Dito de outro modo, tratar-se-ia de colocar no centro da Agenda Social do MERCOSUL um novo e virtuoso modo de articulação entre a política econômica e a política social, em uma estratégia comum que viabilizasse a concretização tanto de um novo modelo de desenvolvimento social quanto a própria e almejada integração social regional. Ao não fazê-lo e, ao contrário, ao eleger projetos de unificação das políticas como objetivo central, a estratégia aparentemente maximalista da Agenda Social do MERCOSUL revela sua verdadeira face minimalista e institucionalmente débil, dada sua inviabilidade.

São bem conhecidas as imensas dificuldades, especialmente para nossos países, de se avançar na direção de um modelo de crescimento como o acima referido, quando as forças ainda hegemônicas da economia internacional globalizada impulsionam na direção contrária. Mas por isso mesmo, além de objetivos propriamente sociais, há objetivos estratégicos e políticos que justificam buscar cada vez mais nas comunidades, nos pactos e nos acordos regionais o apoio para a construção de modelos alternativos e progressistas de desenvolvimento econômico e social.

\section{Resumo}

As políticas sociais se encontram em estágio ainda embrionário nos processos constitutivos do MERCOSUL. Entretanto, desde a segunda metade dos anos 1990, acelerou-se o processo de construção das instituições a elas dedicadas no interior do sistema institucional do mercado comum. Tendo por foco a política de saúde e mais amplamente o sistema de políticas sociais, o artigo rastreia as razões do desequilíbrio através de três movimentos: a reconstituição da trajetória de construção institucional do MERCOSUL social; a identificação e confronto das sucessivas estratégias de formulação e implantação da agenda social da integração; $e$ a reflexão sobre os dilemas e desafios que hoje cercam o tema. O estudo permite afirmar que o MERCOSUL opera com estratégias de difícil conciliação. No plano institucional, orienta-se por uma estratégia minimalista, enquanto que no plano conceitual/discursivo, maneja a estratégia maximalista da unificação supranacional das políticas sociais. O fato é que opera uma estratégia minimalista de políticas sociais, uma vez que abdica de trazer para o campo da integração social o debate e a proposição de modelos de desenvolvimento econômico e social que possam sustentar o processo efetivo de constituição da cidadania social regional.

Política de Saúde; Política Social; Desenvolvimento Econômico 


\section{Referências}

1. Mello FV. MERCOSUL e ALCA: diagnóstico e indicações para atuação. http://www.icd.org.uy/ mercosur/forum/mello.html (acessado em 16/ Jun/2006)

2. Di Pietro Paolo, LJ. La dimensión social del MERCOSUR: Recorrido institucional y perspectivas. http://www.iadb.org/intal/ (acessado em 16/ Mai/2006)

3. Podestá B. MERCOSUR: los primeros pasos del Foro. Gestión 1996; 6 jun.

4. Draibe SM. MERCOSUR: la temática social de la integración desde la perspectiva institucional. http://www.cefir.org.uy/docs/dt17/08draibe.htm (acessado em 16/Jun/2006).

5. Holanda EGM. A saúde no MERCOSUL e integração regional. http://www.ensp.fiocruz.br/parcerias/redsalud (acessado em 24/Mai/2007).

6. Holanda EGM. A saúde no MERCOSUL. 3a Ed. Brasília: Ministério da Saúde, 2005.

7. Ministério da Saúde. A Saúde no MERCOSUL. Brasília, 1999. http://bvsms.saude.gov.br/bvs/ publicacoes/saude_mercosul.pdf (acessado em 24/Mai/2007)

8. Sistemas de Informação em Saúde do MERCOSUL. http://www.mercosulsalud.org/portugues/sgt/ rosgt11/index.htm (acessado em 24/Mai/2007).

9. Lucchese G. Questões estratégicas da integração regional para as políticas e sistemas de saúde no MERCOSUL. http://www.ensp.fiocruz.br/ parcerias/redsalud (acessado em 24/Mai/2007).
10. Guimarães L, Giovanella L. Integração européia e políticas de saúde: repercussões do mercado interno europeu no acesso aos serviços de saúde. Cad Saúde Pública 2006; 22:1795-807.

11. Ministério da Saúde. A saúde no MERCOSUL. 2a Ed. Brasília: Ministério da Saúde; 2003

12. Sistema Económico Latinoamericano y del Caribe. Declaración de la XXIV Reunión del MERCOSUR. http://www.sela.org/public_html/AA2K3/ ESP/cap/N67/cap67-11.htm (acessado em 16/ $\mathrm{Mai} / 2006)$.

13. Ermida UO. La ciudadanía laboral en el MERCOSUR. http://www.ilo.org/public/spanish/ region/ampro/cinterfor/publ/sala/ermida/ ciud_lab/index.htm\#Introducción (acessado em 08/Jun/2007).

14. Holanda EGM. A saúde no MERCOSUL. 3a Ed. Brasília: Ministério da Saúde; 2005.

15. Théret, B. proctetion sociale et federalisme. L'Europe dans le mirroir de l'Amérique du Nord. Montreal: Les Presses de l'Université de Montreal; 2002.

16. Théret, B., L'Etat, la finance et le social. Souveraineté nationale et construction européenne. Paris: La Découverte; 1995.

17. Mkandawire T. Le rétour du development. Courrier de la planete 2002; (67):3-8

Recebido em 14/Jun/2006

Versão final reapresentada em 06/Jun/2007 Aprovado em 06/Jun/2007 